\title{
A ESPECTROSCOPIA RAMAN CONFOCAL NA INVESTIGAÇÃO DA PENETRAÇÃO DE PRODUTO COSMÉTICO DESPIGMENTANTE
}

\author{
Michely Glenda Pereira da Silva ${ }^{1}$ \\ Aline Priscila Campos Pereira ${ }^{2}$ \\ Taciana D. Magrini Alva ${ }^{3}$ \\ Airton A. Martin ${ }^{4}$
}

Resumo: Este trabalho tem como objetivo mostrar a penetração de um produto cosmético despigmentante in vivo, utilizando a espectroscopia Raman confocal. Este estudo envolve 10 mulheres com faixa etária entre 18 a 60 anos, com a pele do antebraço íntegra, e que concordaram em realizar o experimento. $O$ protocolo do experimento foi dividido em 4 passos, com profundidade total de 0 a $100 \mu \mathrm{m}$. Observou-se os picos Raman de números de onda de 785, 1031, 1042 e $1596 \mathrm{~cm}-1$, referentes à presença do produto na pele. Constatou-se a penetração do produto desde a superfície até a derme, e a diminuição da intensidade dos picos 1031 e $1042 \mathrm{~cm}-1$ de acordo com a profundidade. Este estudo mostra a eficácia da utilização da técnica Raman confocal na investigação, análise e monitoramento in vivo da penetração de um produto cosmético com princípio ativo despigmentante.

Palavras-chave: Cosmético; Espectroscopia Raman Confocal; Pele humana.

\footnotetext{
${ }_{1}^{1}$ Doutoranda em Engenharia Biomédica/Instituto de Pesquisa e Desenvolvimento - IP\&D/Universidade do Vale do Paraíba - UNIVAP, Brasil. E-mail: michely.glenda@hotmail.com.

2 Graduação em Ciências Biológicas pela Universidade do Vale do Paraíba, Brasil. E-mail: allinneferrara@gmail.com.

${ }^{3}$ Pós Doutorado da Universidade do Vale do Paraíba, Brasil. E-mail: texying@gmail.com.

4 Professor adjunto da Universidade do Vale do Paraíba. Coordenador do Laboratório de Espectroscopia Vibracional Biomédica e Lab. PROBES- Desenvolvimentos de Projetos em Biomedicina e Engenharias, Brasil. Email: amartin@univap.com.br.
} 